\title{
Developing Students' Global Perspectives in Secondary Chinese Classrooms
}

\author{
GAO Jing \\ Leestown Middle School, Fayette County Public Schools, Lexington, KY, U.S.A.
}

\begin{abstract}
With the development of economy, technology, and international exchanges, the process of globalization has been accelerated. In order to meet the needs of our increasingly complex and changing world, our students need to be prepared for global competence. In language classrooms, we need to enhance students' cultural awareness and develop their global perspectives so that they can be prepared for successfully participating in global affairs and becoming competitive, creative, and humanized citizens in their future. In this paper, the author explores and discusses the strategies that teachers can employ in Chinese classrooms at middle and high schools to develop students' global perspectives.
\end{abstract}

Keywords: global perspectives, global competence, cultural competence, Chinese education, global education

\section{Introduction}

We live in a changing world due to processes of globalization even though societies have been connected with one another to some degree throughout history. Modern communication and transportation networks and new information technologies have made the interconnectedness of different peoples more extensive and intensive. Globalization today implies that many aspects of political, economic, and social activities are becoming interregional or intercontinental in scope, and there has been an intensification of levels of interaction and interconnectedness within and between states and societies (Held, 2000). What happens in one part of the world increasingly affects and is affected by others due to the interconnectedness and interdependence of the system. These changes bring forth important educational implications. Scholars call for today's educators to teach for a global perspective and prepare students to become active and informed citizens in this globalized society (Alger \& Harf, 1986; Hanvey, 1976; Kniep, 1986; Merryfield, 2002; Merryfield \& Wilson, 2005; Pike \& Selby, 1999).

In recent years, China as the second largest world's economy is increasingly playing an important and influential role in the global economy. China is and will be an important economic and business partner of the US. The rise of China presents new economic, political, and social realities that demand greater US engagement at every level. While Chinese language continues to rapidly expand from kindergarten to college classrooms in the US, the language education is inadequate to meet the challenges of contemporary life in the global age. There has been a growing demand for effective, culturally competent, and world-minded Chinese teachers who play

GAO Jing, Ph.D., Leestown Middle School, Fayette County Public Schools. 
significant roles in developing our students' proficiency in Chinese language, global perspectives, and appreciation of cultural diversity for the success in their future workforce. Representing one of the greatest challenges facing education researchers in today's global economy, the goal of world language education is to increase our students' language skills and cultural/global competence, allowing them to successfully interact with the global community both inside and outside our borders (ACTFL, 2014).

In this article, I integrate the five elements in global education into secondary Chinese language classrooms to develop students' cultural awareness and global perspectives. These five elements include resistance to stereotyping, teaching perspective consciousness, cross-cultural learning, global issues, and world interconnectedness. The teaching strategies that discussed in the following sections could create a way for educators to develop students' global perspectives over time and to prepare them for dealing with their involvement in worldwide systems and becoming effective, responsible, and humanized citizens in our interconnected world.

\section{Resistance to Stereotyping}

Pike and Selby (1999) describe stereotypes as "how we often attribute a range of common, often negative, characteristics to groups of people who are or seem different, hence negating their individuality" (p. 154). Often stereotyping occurs when quaint or exotic features of a culture are focused on. Students bring into classrooms their distorted or exotic images of different people and cultures from the media and other influences in the environment, which lack conscious examination and mingle with their prejudice and ethnocentrism (Merryfield \& Wilson, 2005). Resistance to stereotyping provides a powerful stimulus for students to reflect upon and reframe their personal worldviews. This resistance discourages generalizations about people and nations and appreciates sufficient diversity and complexity in groups of people, cultures, and nations.

The first step in teaching students to resist stereotyping is to identify middle and high school students' prior knowledge as well as stereotypes and images of people, cultures, or nations under study. In Chinese classrooms, teachers can have students brainstorm on the relevant topics what they know about Chinese people and culture in general and seek out and identify the knowledge, experiences, and values that shape their worldviews of others in order to understand their decisions or stereotypic interpretation of events or issues. For example, we can start a unit long process of self-reflection with survey at the beginning of the thematic unit of food in middle school Chinese class. Students are asked to write and respond to a list of questions, such as "What is your earliest memory of Chinese food? Do you have favorite Chinese food now, and what is it? What are your beliefs and perspectives on Chinese food?". In the following full-class discussion, we can have students share their personal experiences and questions on food and eating in Chinese culture. Teachers can take this teaching moment giving students the articles, showing them video clips, and teaching about food and eating habits in Chinese culture as well as comparing similarities and differences between Chinese American food and food in China. Finally, we can ask students to speculate on the implications of this lesson for their study of Chinese food. The classroom participation and discussion aims to explore how students' assumptions have been led by their knowledge, experiences, and beliefs, and how their assumptions have shaped interpretations of images, events, and issues. The skills of reflection and critical thinking can be developed with practice and purposeful thought over time. 
Second, to resist stereotyping, teachers need to develop lessons to replace misconceptions or limited knowledge with information and knowledge on the complexity of cultures, cultural conflicts, and global issues. Merryfield and Wilson (2005) suggest that prejudice and stereotyping can be reduced when students engage in activities with new knowledge that disconfirms specific stereotypes and replaces them with new information, and the new information is reinforced through meaningful, real-life experiences. For example, when we recognize students' over-generalized misperception of people in China as poor, uneducated, and starving, we can have students work with maps and statistics on Chinese demographics, read primary source documents such as letters, speeches, or diaries, and watch documentary films that describe middle class young adults' life in China. Gao's article (2008), One Day With a Second Grader in Beijing, provides a diary-like description of one day in the life of an elementary student in Beijing, China. It can be used in Chinese classroom to help students understand the growing up middle class in today's China and their perspectives, values, norms of behaviors beyond the surface culture. When students have more knowledge, we can invite guest speakers (Chinese people who work in different professional fields in the local community and American people who have recently visited China) to come into class and interact with students to reinforce the study with their first-hand life experiences.

Considering the limitation of using visuals to effectively help students overcome stereotypes as many of them are dated, focus on the negative part of Chinese culture, and omit the realities of everyday life for common people, we can employ websites and webcams as powerful resources to have students actually see life in other places in China as it really is and they are mostly not outdated. On the other hand, we can use some secondary source materials when describing some classroom activities to raise students' awareness of stereotypes in learning the relevant issues.

\section{Teaching Perspective Consciousness}

In his work An Attainable Global Perspective, Hanvey (1976) defines the skills of perspective consciousness:

The recognition or awareness on the part of the individual that he or she has a view of the world that is not universally shared, that this view of the world has been and continues to be shaped by influences that often escape conscious detection, and that others have views of the world that are profoundly different from one's own. (p. 5)

Perspective consciousness allows students to recognize how their values, cultural beliefs, and norms of behavior influence their perception and interpretation of events or issues. It also provides an opportunity for students to understand how and why people may see events or issues quite differently.

To teach perspective consciousness, teachers need to develop students' ability to reflect upon their own perspectives, values, norms, beliefs, and experiences which have been accumulated through family, school, and society. It is interwoven with the strategy of resistance to stereotyping.

Teachers also need to incorporate multiple perspectives that people and nations hold about the world, which comprise the deeper layers of values, beliefs, and norms of individuals, groups, and nations regardless of time and space into lessons, help students learn to deal with conflicting information, and develop in them a habit of the mind to look for and examine the views of the marginalized people. In Chinese classrooms, we can use primary sources (such as editorials, speeches, political documents, or websites) and literature written by people in China (autobiographies, children's stories, or historical fiction) within the study of important events and issues. These 
sources create complexity and enrich concept learning. One example is about the study of population in the lesson of introduction to China. We can introduce primary sources by government, majority ethnic Han people, minorities, and other groups with different socio-economic status influenced by one-child policy and new family planning policy in China. We can help students to understand the ways where different groups have experienced and thought about the actions of family planning policies in China and how these policies have affected people's lives today and will affect in future locally, nationally, and globally. It can promote students' skills of tolerance, understanding, and appreciation of multiple perspectives, and their ability to see the complexity of human behavior.

Simulations can be employed as powerful activities to teach perspective consciousness in Chinese classrooms as well. "Simulations allow students to participate in scenarios that imitate certain dynamics of real-life situation" (Anderson, 1994, p. 97). For example, a simulation game called Bafa Bafa can be used to promote students' understanding of perspective consciousness and to explore their assumptions and misconceptions on Chinese cultural customs. This simulation creates an artificial situation, where two groups of students assume specific roles for the Alpha culture and for the Beta culture, following the predefined rules respectively. We can carefully design a set of facilitator instructions, certain student materials, and include suggested questions and instructions for debriefing at the end of the activity. There is also some space for students to bring their prior experience and personal values to the activity in the simulation. Simulations provide a good opportunity for students to use their abilities in dramatization and speech and skills of observation, perspective taking, reasoning, problem solving, and decision making to demonstrate their understanding of others' point of view. Students also actively obtain information about themselves, others, human beings' actions, and the contexts in which the decisions are made.

\section{Cross-Cultural Learning}

In his work An Attainable Global Perspective, Hanvey (1976) defines cross-cultural awareness:

Awareness of the diversity of ideas and practices to be found in human societies around the world, of how such ideas and practices compare, and including some limited recognition of how the ideas and ways of one's own society might be viewed from other vantage points. (p. 10)

There has been extensive research on cross-cultural psychology, sociology, and intercultural communication, including Developmental Model of Intercultural Sensitivity by Bennett (1993). Bennett describes the psychology of people's thought process, and categorizes denial, defense, and minimization in the ethnocentric stages and acceptance, adaptation, and integration in the ethnorelative stages as intercultural development where people learn to value and respond respectfully to others in all cultures. Bennett's model is particularly relevant to how teachers can use appropriate strategies to help students overcome ethnocentrism and develop intercultural competence. For example, if students are at the denial stage, unaware of the existence of cultural difference, or the defense stage, acknowledging cultural differences but feeling threatened by them, we can invite guest speakers (American teachers working in the same school) to share their pictures and videos of Beijing or other places where they visited in China, to demonstrate cultural differences that are obvious but not threatening. 
To develop students' intercultural competence and global perspectives, teachers need to find ways in Chinese classrooms to increase students' cross-cultural learning experiences with people different from themselves. Experience with different people can have a powerful impact on students' global understanding (Merryfield \& Wilson, 2005). We can take students on field trips to Chinese restaurants, stores, concerts, museums, and festivals in the local community, or other places in the United States and overseas. We can invite Chinese students from local exchange high school student programs or universities as cultural consultants in Chinese classrooms to interact with our students and facilitate their learning of China and Chinese culture.

Some resources such as EPals and iEARN as well as sister schools in China can be used as opportunities for students to get connected with peers in China and to develop intercultural competence with a better knowledge and understanding in cross-cultural learning. EPals: Classroom Exchange connects peers around the world through writing email, participating in a discussion board, and engaging in projects, featured with instant language translation technology within an email browser for seven language versions. iEARN: International Education and Resource Network offers projects for students all over the world to participate and collaborate online. We can also exchange materials with peers in sister schools in China through telecommunications linkups. The results of study of the same materials by classes in sister schools can be shared, and compared and contrasted. For example, in the unit "My Daily Life", students can work on the project about American and Chinese teenagers' life with peers at the schools in China. They can exchange emails, write pen-pal letters, or communicate through video conferences (Skype, Wechat) in the target language on certain topics such as daily routine, school experience, class schedules, and family life throughout the unit. At the end, students report their findings about similarities and differences between their daily life and that of peers in China. They can gain insights into their own and Chinese culture through sharing and comparing information on the project.

\section{Teaching Global Issues}

A variety of events and issues happen on the world stage: the advance in technologies, resources shortages, the population explosion, the environmental crisis, the economic crisis, terrorism, the disposal of nuclear wastes, religious conflict, hunger, etc. These issues have emerged as crucial to our earth's survival and the quality of people's lives in the world. The events outside the national borders have increasingly affected the daily lives of people in the US. A global issue is defined by Pike and Selby (1988) as "a contemporary phenomenon affecting the lives of people and/or the health of the planet in a harmful way, such as environmental pollution, racism and the threat of nuclear war" (p. 22).

Scholars have recommended certain global issues to be taught in classrooms. Alger and Harf (1986) propose three global issues: population, food, and energy. Their characteristics are transnational in scope; solved only through multilateral actions; persistence; and, linked to one another. Tye (1999) cites the global issues which were most frequently reported from 52 countries, regarding the question of what issues young people need to understand in his cross-national study of global education. They are ecology and the environment, development issues, intercultural relations, peace and conflict, technology, human rights, and social justice. There are also other issues included: democracy, population, HIV/AIDS, international organizations, racism, sexism, and global citizenship. 
To teach global issues, teachers need to engage students in inquiry about the causes, effects, and potential solutions to the global issues of our time. Through seeing how they affect and are affected by these global problems and issues, students will see how they may be part of global issues and problems, and how they may contribute to their solution. In high schools, Chinese teachers can collaborate with the teachers from other disciplines to teach different aspects of global issues. For example, in studying the issue of development, we can integrate interdisciplinary content related to economic growth, population, political agendas, environmental issues, health, education, and cultural issues into our curriculum. In our unit learning, we need to help students understand relevant historical background of development issues, how the issues have evolved over time and space, and how students can be involved in the search for resolution to these problems. Students can work on and present an inquiry-based authentic research project on the topics that they selected based on their own interests about the world's sustainable development at the end of the unit. The goal is for students to learn about development issues and obstacles, current solutions and organizations, and to find their own solutions or propose plans to solve the problems.

\section{Teaching World Interconnectedness}

Our world features the interconnectedness of human activities. Individuals, groups, and nations are involved in multiple interconnected relationships. The advance of technology has brought people and nations to work together regardless of their geographic locations. Pike and Selby (1999) explain world interconnectedness from four dimensions: spatial dimension - local to global interdependent systems; issues dimension-local/global issues, interconnections between issues, and perspectives; temporal dimension-interactive phases of time, alternative futures, and action; and, inner dimension— journey inwards, teaching/learning processes, and medium and message.

Such connections bind all peoples, cultures and countries into a dynamic, ever-changing system in which an event occurring, an action taken, or a decision made at one point on the globe can have multiple repercussions, both now and in the future, in countless other places. (Pike \& Selby, 1999, p. 54)

It is critical to teach students to understand and appreciate world interconnectedness. Teachers need to help students to seek beyond a simple notion of cause and effect and explore the hidden complexity or variables that alter phenomena in the interconnected world, recognize how their thoughts and behaviors would affect and be affected by other nations and peoples in the world, and ultimately be able to participate effectively and responsibly in the world through seeing their place as actors within these global systems.

To teach world interconnectedness, teachers need to involve students in the experiences of the local and global connections. One example in the middle school Chinese classrooms is the Silk Road unit that we can collaborate with social studies teachers. We can have students work in groups and research on commodities exchanged, religions and technology spread along the Silk Road. Some of the guiding questions could be: What items were exchanged on the Silk Road? Where did they come from? How were religions spread along the trade route in all directions? What were the technologies and inventions acquired by China from the West and what were those acquired by the West from Asia? We can give students detailed instructions on the resources including maps, articles, websites, and videos, use a broad range of geographic, economic, political, and cultural literacy, and follow with in-depth discussion questions such as "How could merchants profit from trading goods along the 
Silk Road? How might a country enhance political power by using the Silk Road?". Students can also practice and develop the skills of relational thinking - "seeking connections, relationships and patterns among diverse ideas, experiences and other phenomena" (Pike \& Selby, 1999, p. 55), cooperative learning, graphic and/or mapping skills, analytical thinking, research and information gathering, and decision-making. At the end of the unit, we can have students write an essay about comparing and contrasting the Roman Empire's connection to China and the Silk Road and the United States' connection with China and modern trade, to make a connection between history and modern times and to identify local-global links. It can help students better understand the complexities behind modern trade and explore how their community is in local to global interconnected system and faces local-global challenges and opportunities. Students can document and analyze the global connections encountered in their life and write down opportunities that local people have to affect global conditions.

\section{Conclusion}

Globalization has brought forth huge implications for the development of pedagogical practice and educational preparation for school youth. Our increasingly complex, unpredictable, and changing world requires students to be prepared for global perspectives so that they can cope with a more pluralistic, intertwined, and international system.

In this article I discussed five strategies - resistance to stereotyping, teaching perspective consciousness, cross-cultural learning, teaching global issues, and teaching world interconnectedness in secondary Chinese classrooms. These five strategies are interrelated and cannot be separated for either understanding or practice in teaching. They are powerful strategies for teachers to help students understand diverse cultural perspectives at a deeper level, the role world cultures and economies play, and how what happens in China can impact the US besides students' acquisition of Chinese language skills. Teaching and learning about the world is also interdisciplinary, active, and connected to daily life. Our students need to be engaged with diverse global topics and cultures and to learn skills so that they are able to analyze problems, identify underlying assumptions, and take effective and responsible actions to change conditions that challenge our globalized society.

\section{References}

Alger, C. F., \& Harf, J. E. (1986). Global education: Why? for whom? about what? In R. E. Freeman (Ed.), Promising practices in global education: A handbook with case studies (pp. 1-13). New York: The National Council on Foreign Language and International Studies.

American Council on the Teaching of Foreign Languages (ACTFL). (2014). Global Competence Position Statement.

Anderson, C. C. (1994). Global understandings: A framework for teaching and learning. Alexandria, VA: Association for Supervision and Curriculum Development.

Bennett, M. J. (1993). Towards ethnorelativism. In R. M. Paige (Ed.), Education for the intercultural experience (pp. 21-69). Yarmouth, ME: Intercultural Press Inc..

ePals. (n.d.). Retrieved from www.epals.com/

Gao, J. (2008). One day with a second grader in Beijing. Social Studies and the Young Learner, 20(4), 4-8.

Hanvey, R. G. (1976). An attainable global perspective. New York: Center for War/Peace Studies.

Held, D. (2000). Democracy and globalization. In D. Archibugi (Ed.), Re-imagining political community (pp. 11-27). Stanford, CA: Stanford University Press.

International Education and Resource Network. (n.d.). Retrieved from www.iearn.org

Kniep, W. M. (1986). Defining a global education by its content. Social Education, 50, 437-446.

Merryfield, M. M. (2002). What a difference a global education can make. Educational Leadership, 60(2), 18-21. 
Merryfield, M. M., \& Wilson, A. (2005). Social studies and the world: Teaching global perspectives. San Jose, CA: Cowan Creative.

Pike, G., \& Selby, D. (1988). Global teacher, global learner. London: Hodder \& Stoughton.

Pike, G., \& Selby, D. (1999). In the global classroom: Volumes $1 \& 2$. Toronto, Canada: Pippen.

Tye, K. A. (1999). Global education: A worldwide movement. Orange, California: The Interdependence Press. 